\title{
Impact of Fine Sediment on TSS and Turbidity in Retention Structure
}

\author{
Tan Kah Hern1, Lai Sai Hin1, Shaliza Ibrahim1, Nik Meriam Nik Sulaiman², Mona Sharifi1, \\ Sandra Abe ${ }^{1}$ \\ ${ }^{1}$ Department of Civil Engineering, Faculty of Engineering, University of Malaya, Kuala Lumpur, Malaysia \\ ${ }^{2}$ Department Chemical Engineering, Faculty of Engineering, University of Malaya, Kuala Lumpur, Malaysia \\ Email: laish@um.edu.my
}

Received April 2014

\begin{abstract}
A study of the impact of fine sediment on various water quality parameters in retention structure such as sediment basin was conducted on stagnant and flowing condition. 7 water quality parameters (pH, TSS, turbidity, DO, BOD, COD, ammonium nitrogen) were measured and classified according to the Interim National Water Quality Standard (INWQS) for Malaysia. Results show higher fine sediment concentration causes higher TSS and turbidity. Besides, results show TSS and turbidity were influenced by soil type for the same amount of fine sediment. Soil Siri Rasau 1 showed highest TSS and turbidity value followed by soil Siri Bungor and soil alluvium. A good positive correlation of TSS versus turbidity and has been investigated in this study. Multiple nonlinear regression analysis revealed that parameter TSS is dependent on time, total soil mass, fine soil mass and flow rate.
\end{abstract}

\section{Keywords}

Fine Sediment, TSS, Turbidity, Water Quality

\section{Introduction}

Nowadays, Malaysia faces many challenges in controlling the quantity and quality of stormwater runoff. Stormwater runoff is the major contributor to river pollution (Nazahiyah et al., 2007). One way of controlling increased runoff due to urbanization and social-economic development is to build stormwater management facilities, such as retention/detention ponds. A retention basin is a part of drainage system to control water flow and trap those contaminated solid particles along with the water flow (Lee et al., 1997).

The primary removal mechanism of the retention ponds gravitational settling of those contaminated solid particle especially those with nutrients will affect the biological activity in the pond. Previous study showed that freshwater wetland interaction with sediment affect surface water quality (Johnston, 1991). Most of the retentions ponds are suffered from water pollution problems such as siltation, sedimentation, accumulation of toxic material, algae bloom and so on. Such a condition can also cause a number of social, health and environmental problems, such as odour smell, disease, poor aesthetic value in the surrounding area.

How to cite this paper: Hern, T. K., Hin, L. S., Ibrahim, S., Sulaiman, N. M. N., Sharifi, M., \& Abe, S. (2014). Impact of Fine Sediment on TSS and Turbidity in Retention Structure. Journal of Geoscience and Environment Protection, 2, 1-8. 
Nevertheless, it is hard to monitor all water quality parameters regularly even if adequate manpower and laboratory facilities are provided. Therefore an alternative approach based on statistical correlation and analysis has been used to study the relationship of the water parameters (Bhandari et al., 2008; Shrestha et al., 2007).

In this study the parameters $\mathrm{pH}$, TSS, turbidity, DO, BOD, COD and ammonium nitrogen of different concentration of fine sediment were measured. The effect of soil type on TSS and turbidity has been investigated and the correlation of TSS and turbidity has been studied. Multiple nonlinear regression analysis has been applied.

\section{Experimental Considerations}

The samples of 4 different types of commonly found soil series were collected for this experimental investigation. The characteristics of soil samples are shown in Table $\mathbf{1}$.

A special design experiment tank was designed to investigate the impact of fine sediment on water quality in retention structure. The sediment basin consisting two glass tanks named Tank A and Tank B with dimension of $120 \mathrm{~cm} \times 90 \mathrm{~cm} \times 75 \mathrm{~cm}$ and $75 \mathrm{~cm} \times 90 \mathrm{~cm} \times 75 \mathrm{~cm}$ respectively, water pump, valves and flow meter as shown in Figure 1.

For stagnant condition, different weight of soil $(0.5 \mathrm{~kg}, 1 \mathrm{~kg}$ and $1.5 \mathrm{~kg})$ were mixed with $50 \mathrm{~cm}$ height of clean water in Tank A. Parameters pH, dissolved oxygen (DO) were measured in-situ by Water Quality Model whereas TSS was measured by TSS meter and turbidity measured by spectrometer for different time interval (initial time, 15 minutes, 30 minutes, 1 hour, 3 hours, 6 hours, 1 day, 2 days and 7 days). Standard procedures were used for water collection and water sample analysis for parameter BOD, COD and ammonium nitrogen (APHA, 1995).

For moving condition, $1 \mathrm{~kg}$ of soil was well mixed with $70 \mathrm{~cm}$ height of clean water in tank A and allowed to circulate into tank B with different flow rate (2 LPM, 7.5 LPM and 13 LPM) until equilibrium of height of both tanks were achieved.

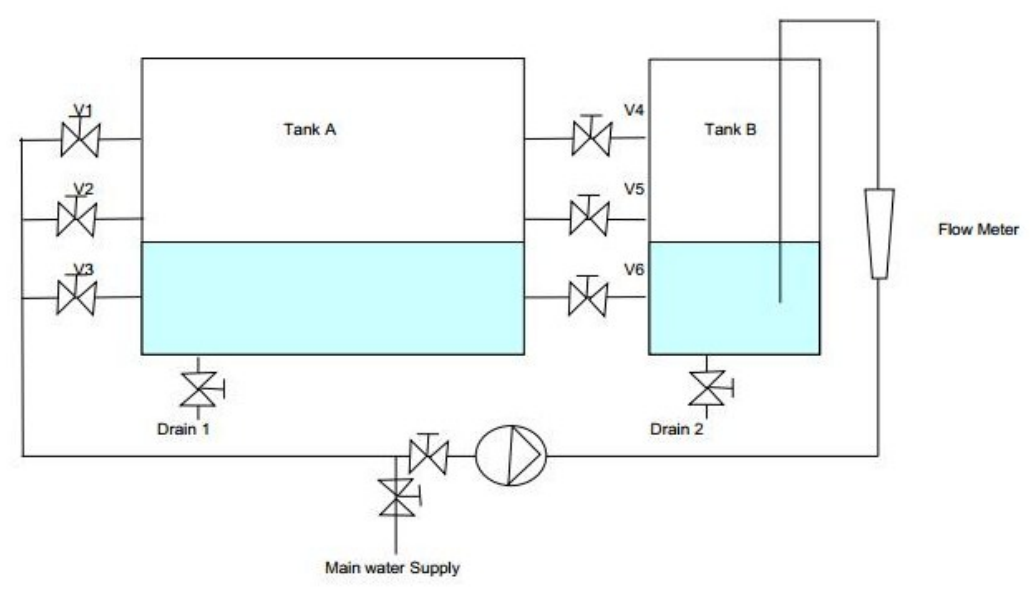

Figure 1. Schematic diagram of the laboratory model.

Table 1. Soil type description.

\begin{tabular}{ccccc}
\hline \multirow{2}{*}{$\begin{array}{c}\text { Soil } \\
\text { properties }\end{array}$} & Sample 1 & Sample 2 & Sample 3 & Sample 4 \\
\cline { 2 - 5 } & 80 & 63 & 35 & 35 \\
Sand\% & 8 & 19 & 11 & 31 \\
Silt\% & 12 & 18 & 54 & 44 \\
Clay\% & Loamy sand & Sandy clay loam & Clay & Clay \\
Texture & 1.348 & 1.274 & 1.222 & 1.214 \\
Bulk density g/cm ${ }^{3}$ & Aluvium & Siri Bungau & Siri Rasau 1 & Siri Rasau 2 \\
\hline
\end{tabular}


Different weight of fine sediments ( 0.5 g, 1 g, 2 g, 3 g, 4 g, 5 g, 6 g, 8 g, 10 g and 12 g) of different soil type (Sample 1, 2 and 3) were mixed with 2 litre of distilled water and parameters TSS and turbidity were measured.

Statistical analysis of data was investigated using SPSS version 20. Karl-Pearson correlation coefficient was calculated. Multiple nonlinear regression analysis is used to analyse the correlation of TSS to time, total soil mass, fine soil mass and flow rate. Several models of different combination of parameters have been tested to study the best model for analysis. Power function (Equations (1) and (2)) is used to analyze the correlation and relationship between TSS and other parameters.

General equation used is as shown in Equation (1).

$$
\mathrm{Y}=\mathrm{b}_{0}\left(\mathrm{X}^{\mathrm{b}_{1}}\right) \text { for function of } \mathrm{X}
$$

where $\mathrm{b}_{0}, \mathrm{~b}_{1}$ are constant.

For multiple variables of function, the general equation is shown in Equation (2).

$$
\mathrm{Y}=\mathrm{b}_{0}\left(\mathrm{X}_{1}^{\mathrm{b}_{1}}\right)\left(\mathrm{X}_{2}^{\mathrm{b}_{2}}\right)\left(\mathrm{X}_{3}^{\mathrm{b}_{3}}\right) \ldots\left(\mathrm{X}_{\mathrm{n}}^{\mathrm{b}_{\mathrm{n}}}\right)
$$

where $\mathrm{b}_{0}, \mathrm{~b}_{1}, \mathrm{~b}_{2}, \mathrm{~b}_{3}$ and $\mathrm{b}_{\mathrm{n}}$ are constant.

\section{Results and Discussion}

From the result obtained, concentration of fine sediment in water is found greatly influence the TSS and turbidity. However, the impact of fine sediments on $\mathrm{pH}, \mathrm{DO}, \mathrm{BOD}, \mathrm{COD}$ and ammonium nitrogen is not obvious. The condition and the amount of fine sediments in each type of testing samples are shown in Table 2. $\mathrm{pH}$ of the aquatic systems is a crucial indicator of the water quality and pollution (Jonnalagadda et al., 2001). The pH value range for samples are 6.89 - 7.4 for TW, 6.77 - 7.40 for S1, 6.74 - 7.11 for S2, 6.50 - 6.88 for S3, 6.55 - 7.40 for F1, $6.56-7.12$ for F2 and 6.81 to 6.97 for F3.

The variations of $\mathrm{pH}$ values of all samples throughout the experimental works (in 7 days) are within 6.5 - 8.5 . $\mathrm{pH}$ value is determined by the amount of dissolved carbon dioxide. It forms carbonic acid when dissolves in water (Sawyer et al., 2007). The $\mathrm{pH}$ value of all samples was observed to have minute change within 7 days (Table 3). It is observed that all samples containing fine sediment have slightly lower $\mathrm{pH}$ value range compared to tap water, TW.

Table 2. Experimental and sample description.

\begin{tabular}{cccc}
\hline \multirow{2}{*}{ Sample name } & \multicolumn{3}{c}{ Description } \\
\cline { 2 - 4 } & Flow rate (LPM) & Total amount of sediment TS, (g) & Amount of fine sediment in TS (g) \\
\hline TW & 0 & 0 & 0 \\
S1 & 0 & 500 & 47 \\
S2 & 0 & 1000 & 87 \\
S3 & 0 & 1500 & 174 \\
F1 & 2 & 1000 & 100 \\
F2 & 7.5 & 1000 & 133 \\
F3 & 13 & 1000 & 181 \\
\hline
\end{tabular}

Table 3. pH range of samples.

\begin{tabular}{ccc}
\hline \multirow{2}{*}{ Sample name } & \multicolumn{2}{c}{ Descriptions } \\
\cline { 2 - 3 } & Soil series & $\mathrm{pH}$ \\
\hline TW & Nil & $6.89-7.40$ \\
S1 & Siri Rasau 2 & $6.77-7.40$ \\
S2 & Siri Rasau 2 & $6.74-7.11$ \\
S3 & Siri Rasau 2 & $6.50-6.88$ \\
F1 & Siri Rasau 2 & $6.55-7.40$ \\
F2 & Siri Rasau 2 & $6.56-7.12$ \\
F3 & Siri Rasau 2 & $6.81-6.97$ \\
\hline
\end{tabular}


TSS indicates the concentration of suspended particles in a liquid effluent (Queenan et al., 1978). Land erosion is one of the contributors of suspended sediments and siltation (Eisakhani et al., 2009). Figure 2 revealed that the higher the Soil sample content, the higher the TSS value at initial concentration. Samples S3 has the highest initial TSS value that is $180 \mathrm{mg} / \mathrm{L}$ followed by S2 with $118 \mathrm{mg} / \mathrm{L}$ and S1 with $55 \mathrm{mg} / \mathrm{L}$. The higher the soil content, the higher the turbidity value. For flowing water, F3 has higher TSS compared to F2 and F1. All samples had great reduction of TSS value within 60 minutes and the TSS values had reduced to almost half of their initial concentration due to settling of the large particles in sample which is more than $63 \mu \mathrm{m}$. Particles in stagnant water are settling faster than moving water when the time increased. At the day 7, all samples had low TSS value range from 3 to $12 \mathrm{mg} / \mathrm{L}$. Suspended solid is one of natural pollutant which contains organic matter and transported by urban storm runoff (Gandaseca et al., 2011).

Suspended particles like silt, clay, organic matter and so on decrease clarity of water and result the turbidity. The murkier water means the higher amount of sediment (Yisa et al., 2010). Generally, siltation increases the turbidity of the water and deteriorates water quality significantly (Astel et al., 2006). Turbidity of all the samples is observed to have the similar trend with the TSS over time (Figure 3). For stagnant water, sample S3 is shown

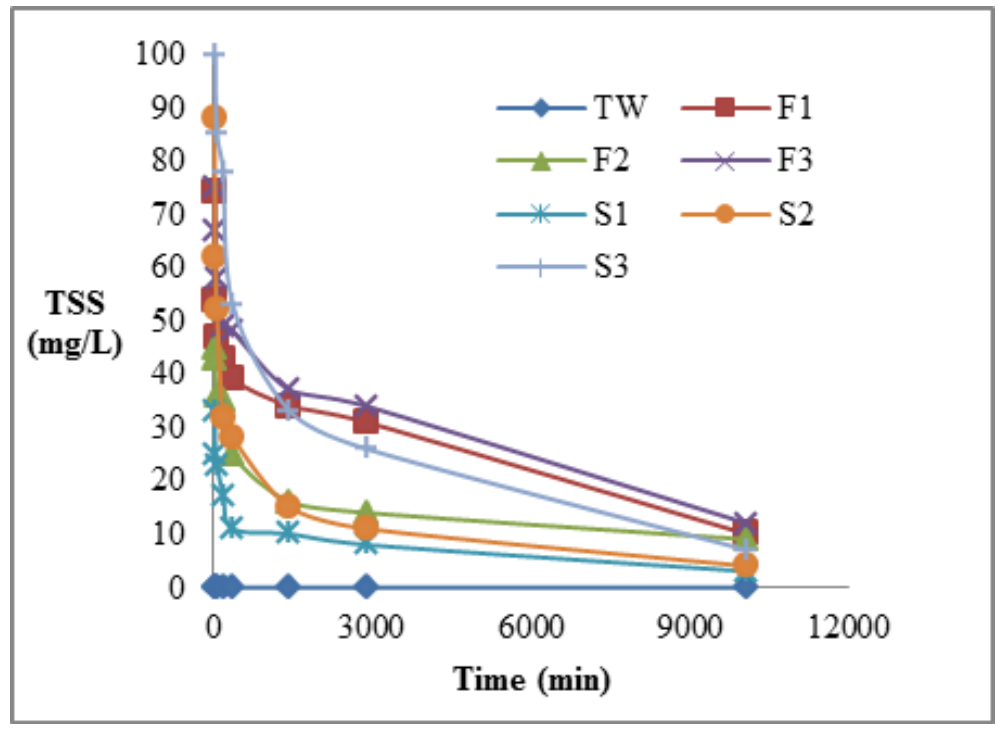

Figure 2. Total suspended solid (TSS) over time.

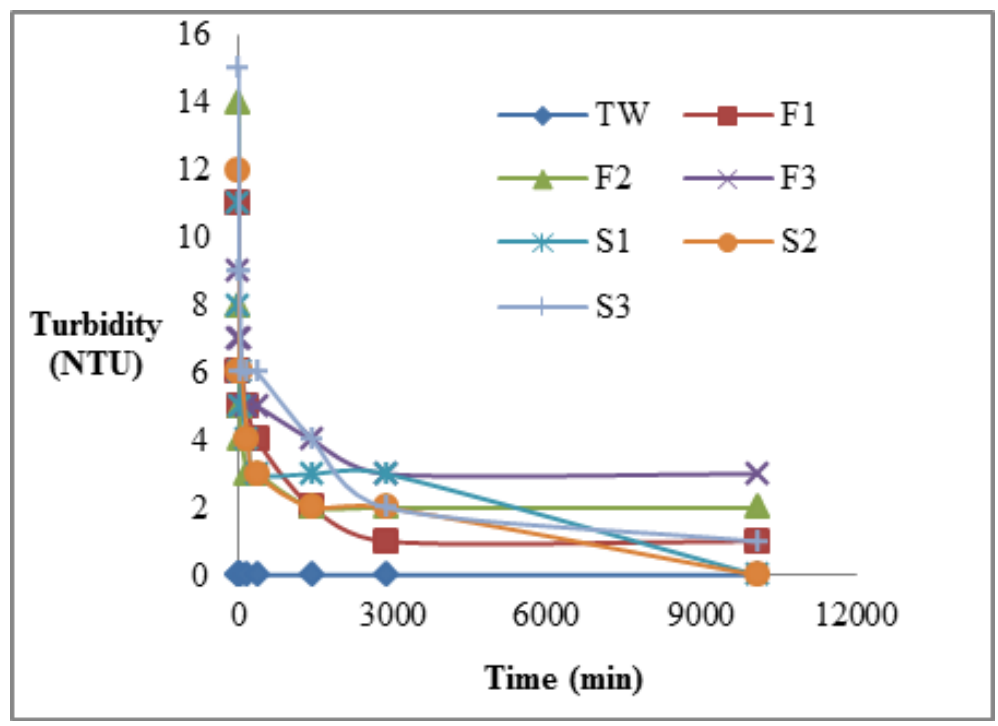

Figure 3. Turbidity over time. 
to have the highest initial turbidity of 15 NTU followed by S2 with 12 NTU, S1 with 11 NTU. For flowing water, F3 has higher turbidity compared to F2 and F1. Initial turbidity is higher when the flow rate is higher. For the first hour, all the samples had reduction of turbidity for about $50 \%$ compared to initial turbidity. At day 7 , all samples had low value of turbidity range 0 - 3 NTU.

Oxygen from the atmosphere and photosynthesis by the aquatic plants becomes dissolved in surface water and it is consumed by the decay of organic particles in water (Astel et al., 2006). The concentration of DO over time is shown in Figure 4. The initial DO concentration for samples are $7.8 \mathrm{mg} / \mathrm{L}$ for tap water, 7.7 for S1, 7.6 for S2, 7.5 for S3 and 7.4 for F1, F2 and F3. It is observed that tap water has the highest value of DO concentration. All the samples had the slightly lower value of DO concentration compared to tap water. Nonetheless, fine sediment does not cause the water to have low DO concentration as fine sediment does not provide nutrient for the decaying of organic matter in water. At day 7, it is observed that samples in flowing condition had 7.2 mg/L of DO concentration, which is slightly higher than the samples in stagnant condition. The increasing in low of water results a great mixing of the atmospheric oxygen with water (APEC, 2011). Therefore flowing water is having higher DO concentration relative to the stagnant water.

It is investigated that parameters of BOD, COD and ammonium nitrogen is similar with drinking water and it is within the range for safe drinking water.

Total suspended solid (TSS) and turbidity were observed for different soil type. The impact of fine sediment on TSS and turbidity are not fixed but depend on proportion of clay content. From Figure 5, it showed that TSS

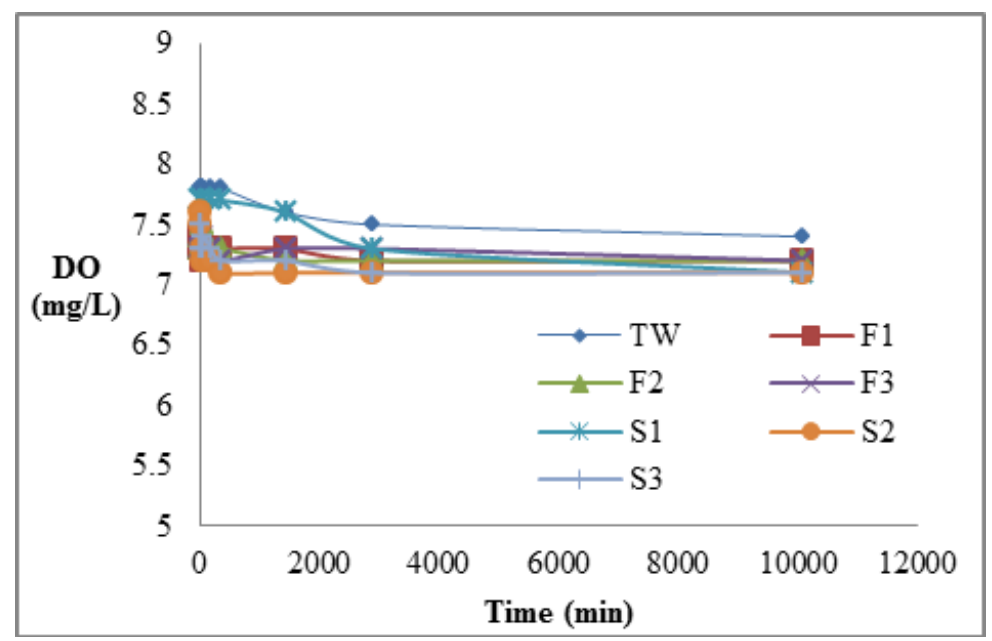

Figure 4. DO over time.

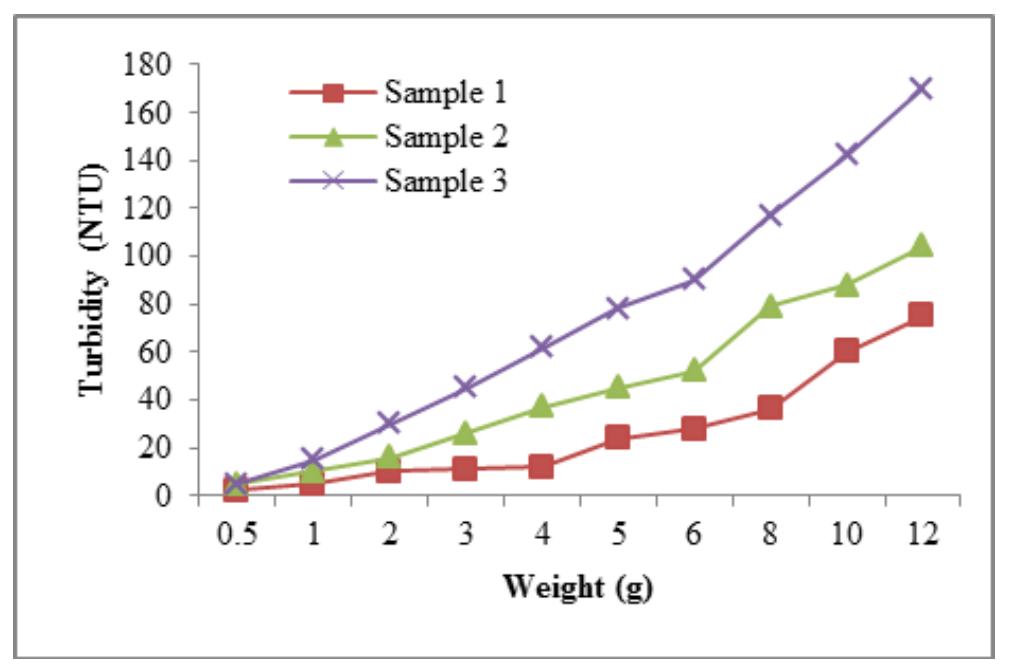

Figure 5. Total suspended solid (TSS) at varying weight of the fine sediment. 
increased with the weight of fine sediments for all types of soil sample. Sample 1 with clay content of $54 \%$ had the highest TSS value at varying weight of fine sediment, followed by Siri Bungor and Aluvium with clay content of $18 \%$ and $12 \%$ of clay content respectively. It is because the higher the content of clay, the higher the value of TSS and turbidity. TSS for all types of soil sample increased steadily from $0.5 \mathrm{~g}$ until $6.0 \mathrm{~g}$ and increased rapidly from $6.0 \mathrm{~g}$ until $12.0 \mathrm{~g}$. At $8.0 \mathrm{~g}$, the TSS rapidly increased to $593 \mathrm{mg} / \mathrm{L}, 1450 \mathrm{mg} / \mathrm{L}$ and 2550 $\mathrm{mg} / \mathrm{L}$ for soil sample type 1, 2 and 3 respectively. The highest value of TSS achieved was $721 \mathrm{mg} / \mathrm{L}, 2500 \mathrm{mg} / \mathrm{L}$ and $3950 \mathrm{mg} / \mathrm{L}$ for Sample 1, 2 and 3 respectively.

The effect of weight of fine sediments on the turbidity was also investigated. Previous study has shown that suspended silt concentration gravimetrically gives a linear relationship with turbidity (Divakaran et al., 2011). The results are shown in Figure 6. Turbidity increased with the increasing of the weight of fine sediments for all types of soil sample. It is observed that turbidity at varying weight of fine sediment had the similar trend with the TSS. Soil sample type 3 has the highest turbidity achieved at varying weight of fine sediment followed by type 2 and type 1 . All soil samples achieved highest turbidity value at $12 \mathrm{~g}$ weight of fine sediment i.e. $75 \mathrm{NTU}$, 104 NTU and 170 NTU for soil Sample 1, 2 and 3 respectively.

Past studies had been conducted and consistently showed a good correlation between TSS and turbidity (Ali et al., 2013). Relationship between TSS and turbidity is shown in Figure 7. Generally the plotted data showed a good positive correlation relationship between TSS and turbidity with a coefficient of determination, $\mathrm{R}^{2}=$ 0.9505 .

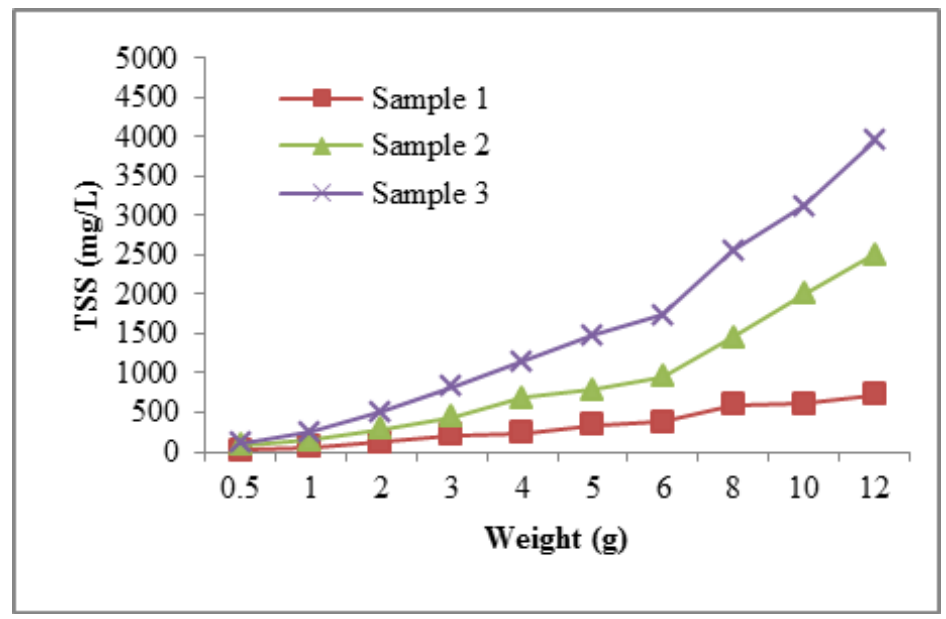

Figure 6. Turbidity at varying weight of the fine sediment.

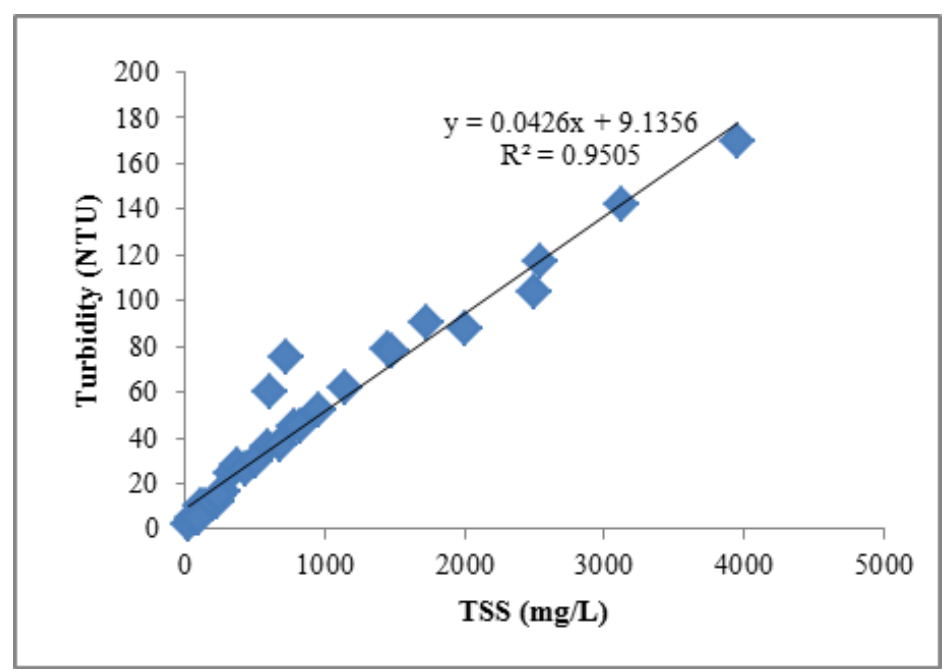

Figure 7. Correlation between TSS and turbidity. 


\section{Statistical Analysis}

Statistical analysis has been widely used in analyzing the correlation of TSS to other parameters (Ali et al., 2013; Bhandari et al., 2008; Shrestha et al., 2007). Referring to the result above, TSS value is decreasing for time and the early stage settlement is due to coarse sediment settled down and later stage is due to the settlement of fine sediment. Therefore time, total sediment mass, fine sediment mass and flow rate in all cases. Correlation value between TSS with time, total sediment mass, fine sediment mass and flow rate is shown in Table 4. A negative correlation was found between TSS and time $(r=-0.503)$. This shows that the increasing of time will cause the TSS to exhibit a decrease in value. Positive correlation was found between TSS and total soil mass $(r=0.439)$, TSS and fine soil mass $(r=0.419)$ and TSS and flow rate $(r=0.009)$. Value of TSS will increase or decrease with the increase or decrease or total soil mass, fine soil mass and flow rate. Multiple nonlinear regression analysis has been used to analyze the correlation between TSS with time, total sediment mass, fine sediment mass and flow rate. The equation of estimated TSS is shown is equation 3 with coefficient of determination, $\mathrm{R}^{2}=$ 0.908 .

$$
\mathrm{TSS}=0.166 \mathrm{t}^{-0.2} \mathrm{TS}^{0.803} \mathrm{FS}^{0.204} \mathrm{FR}^{-0.003}
$$

Therefore, positive correlation is observed from the multiple non-linear regression analysis and is shown in Figure 8. We can observe that the predicted TSS is almost similar to the observed TSS with $\mathrm{R}^{2}=0.9098$. This showed that parameter TSS is affected by time, total sediment mass, fine sediment mass and flow rate as well.

\section{Conclusion}

This study showed the effect of fine sediment to the water quality in retention structure with clean water under stagnant and flowing condition. It is observed that water quality parameters are influenced by fine sediments. Fine sediment greatly affects the turbidity and TSS value whereas the effect on $\mathrm{pH}, \mathrm{DO}, \mathrm{BOD}, \mathrm{COD}$ and ammonium nitrogen is not obvious. Higher silt and clay content in soil sample will have higher turbidity and TSS

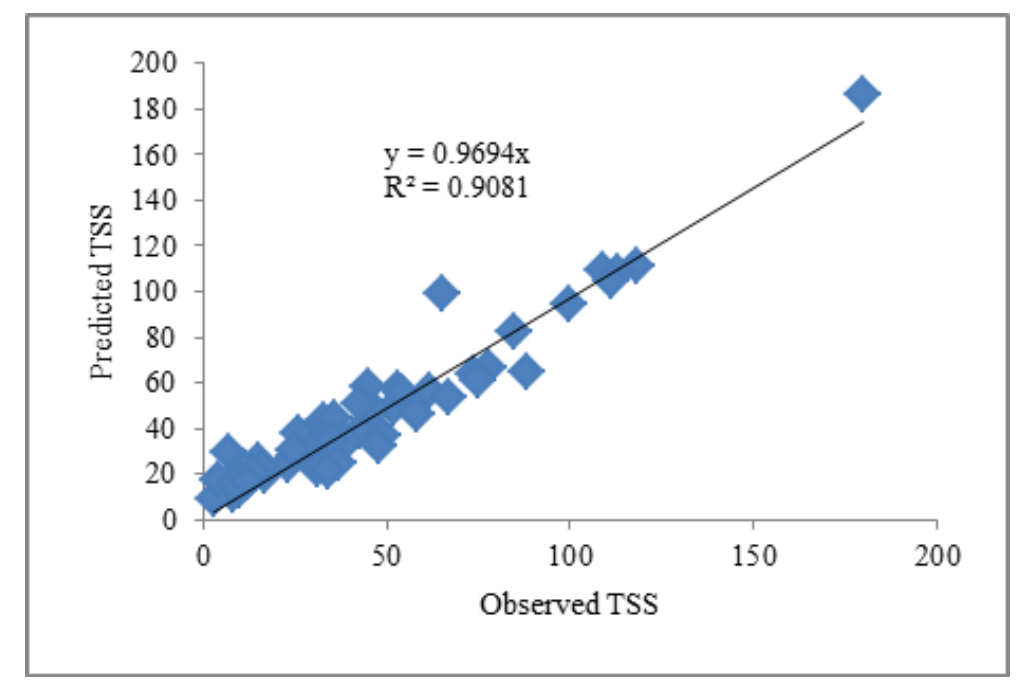

Figure 8. Correlation of predicted TSS versus observed TSS.

Table 4. Coefficient of correlation for TSS.

\begin{tabular}{ccc}
\hline \multirow{2}{*}{ Parameter } & \multicolumn{2}{c}{ Parameters and coefficient of determination } \\
\cline { 2 - 3 } & Parameters & $\mathrm{R}$ \\
\hline \multirow{2}{*}{ TSS } & Time & -0.503 \\
& Total soil mass & 0.493 \\
& Fine soil mass & 0.419 \\
\hline
\end{tabular}


value compared to those lower silt and clay content for the same amount of fine sediment. We investigated that settlement of fine sediments depends on time, total sediment mass, fine sediment mass and flow rate. A good positive correlation relationship between TSS and turbidity with a correlation coefficient of $\mathrm{R}^{2}=0.9505$. However further study on fine sediment will be conducted for actual pond water.

\section{Acknowledgements}

The authors are grateful to the Government of Malaysia for the financial support through the UMRG grant no. RP008B-13SUS and FRGS grant no. FP028-2012A. The authors thank also the faculty of engineering for the facilities provided for this research work.

\section{References}

Ali, Z. M., Ibrahim, N. A., Mengersen, K., Shitan, M., \& Juahir, H. (2013). New Relative Importance of Water Quality Variables in Langat River. International Journal of Chemical \& Environmental Engineering, 4.

APEC (2011). APEC Water Systems: Free Drinking Water, Learn about Water Quality. http://www.freedrinkingwater.com/water_quality/quality1/1-how-dissolved-oxygen-affects-water-quality-htm

APHA (2005). Standard Methods of Water and Wastewater (21st ed.). Washington DC: American Public Health Association.

Astel, A., Biziuk, M., Przyjazny, A., \& Namieśnik, J. (2006). Chemometrics in Monitoring Spatial and Temporal Variations in Drinking Water Quality. Water Research, 40, 1706-1716. http://dx.doi.org/10.1016/j.watres.2006.02.018

Bhandari, N. S., \& Nayal, K. (2008). Correlation Study on Physico-Chemical Parameters and Quality Assessment of Kosi River Water, Uttarakhand. Journal of Chemistry, 5, 342-346.

Divakaran, R., \& Sivasankara Pillai, V. N. (2002). Flocculation of River Silt Using Chitosan. Water Research, 36, 24142418. http://dx.doi.org/10.1016/S0043-1354(01)00436-5

Eisakhani, M., \& Malakahmad, A. (2009). Water Quality Assessment of Bertam River and Its Tributaries in Cameron Highlands, Malaysia. World Applied Sciences Journal, 7, 769-776.

Gandaseca, S., Rosli, N., Ngayop, J., \& Arianto, C. I. (2011). Status of Water Quality Based on the Physico-Chemical Assessment on River Water at Wildlife Sanctuary Sibuti Mangrove Forest, Miri Sarawak. American Journal of Environmental Sciences, 7. http://dx.doi.org/10.3844/ajessp.2011.269.275

Johnston, C. A. (1991). Sediment and Nutrient Retention by Freshwater Wetlands: Effects on Surface Water Quality. Critical Reviews in Environmental Science and Technology, 21, 491-565.

Jonnalagadda, S. B., \& Mhere, G. (2001). Water Quality of the Odzi River in the Eastern Highlands of Zimbabwe. Water Research, 35, 2371-2376. http://dx.doi.org/10.1016/S0043-1354(00)00533-9

Lee, P. K., Touray, J. C., Baillif, P., \& Ildefonse, J. P. (1997). Heavy Metal Contamination of Settling Particles in a Retention Pond along the A-71 Motorway in Sologne, France. Science of the Total Environment, 201, 1-15. http://dx.doi.org/10.1016/S0048-9697(97)84048-X

Nazahiyah, R., Yusop, Z., \& Abustan, I. (2007). Stormwater Quality and Pollution Loading from an Urban Residential Catchment in Johor, Malaysia. Water Science \& Technology, 56. http://dx.doi.org/10.2166/wst.2007.692

Sawyer, C. N., \& McCarty, P. L. (1978). Chemistry for Environmental Engineering (3rd ed.). New York: McGraw-Hill Book Co.

Yisa, J., \& Jimoh, T. (2010). Analytical Studies on Water Quality Index of River Landzu. American Journal of Applied Sciences, 7. http://dx.doi.org/10.3844/ajassp.2010.453.458 